\title{
Pettigrew Syndrome
}

National Cancer Institute

\section{Source}

National Cancer Institute. Pettigrew Syndrome. NCI Thesaurus. Code C124839.

A rare, $\mathrm{X}$-linked inherited syndrome characterized by mental retardation and additional features, which include choreoathetosis, hydrocephalus, Dandy-Walker malformation, seizures, and iron or calcium deposition in the brain. 